\title{
MaxEnt (Maximum Entropy) model for predicting prehistoric cave sites in Karst area of Gunung Sewu, Gunung Kidul, Yogyakarta
}

Luthfi Alwi Muttaqin, Sigit Heru Murti, Bowo Susilo

Luthfi Alwi Muttaqin, Sigit Heru Murti, Bowo Susilo, "MaxEnt (Maximum Entropy) model for predicting prehistoric cave sites in Karst area of Gunung Sewu, Gunung Kidul, Yogyakarta," Proc. SPIE 11311, Sixth Geoinformation Science Symposium, 113110B (21 November 2019); doi: 10.1117/12.2543522

Event: Sixth Geoinformation Science Symposium, 2019, Yogyakarta, Indonesia 


\title{
MaxEnt (Maximum Entropy) Model for Predicting Prehistoric Cave Sites In Karst Area Of Gunung Sewu, Gunung Kidul, Yogyakarta
}

\author{
Luthfi Alwi Muttaqin ${ }^{\mathrm{a}}$, Sigit Heru Murti B. S. ${ }^{\mathrm{b}}$, Bowo Susilo ${ }^{\mathrm{b}}$ \\ ${ }^{a}$ Post Graduate Student of Remote Sensing Program, Faculty of Geography, Universitas Gadjah \\ Mada; ${ }^{b}$ Lecturer of The Faculty of Geography, Universitas Gadjah Mada
}

\begin{abstract}
Gunungsewu is a karstic region in the southern part of Java Island, Indonesia. That area has a various type of archaeological evidences including human remains, animal remains, bone artifacts, stone artifacts, and shell artifacts which found in prehistoric caves, that show evidence of occupation caves as sustain of prehistoric human communities. In order to enhance the future of archaeological research, MaxEnt Model used to estimate Prehistoric occupation cave sites in the karstic region of Gunung Sewu. The objectives of this research are: (1) (1) Assessing the ability of DEM Alos Palsar, Sentinel-2a images and GIS data to extract environmental parameters related to prehistoric occupation cave sites. (2) Preparing a spatial model to estimate prehistoric occupation cave sites using DEM Alos Palsar imagery, Sentinel-2a imagery, and GIS data for input model MaxEnt (maximum entropy). (3) the accuracy of MaxEnt model to predicting location of prehistoric occupation caves. Primary data consist of environmental variables and caves variables analyzed by MaxEnt Model. Those variables extracted from 12.5-meter resolution DEM Alos Palsar, Sentinel- 2A images with 10 meters resolution, and GIS data. Environmental variables assessed by several maps such as valley-hill classification (OBIA), distance of valley, elevation, slope, aspect, distance of lineament, lineament density and distance from water sources. Input data used 68 location prehistoric cave sites and 8 environmental variables with AUC value of 0.715 in good performance. Modeling process results are the jackknife test, response curve of the environmental variables, and probability map. Based on the probability map, this research is able to obtained prehistoric cave location data. Therefore, the ability of MaxEnt model as a method to locate archeological sites becomes reliable.
\end{abstract}

Keywords: Modeling, MaxEnt, Maximum Entropy, Prehistoric Site, Karst Area, Gunung Sewu, Gunung Kidul, Sentinel-2A, Alos Palsar DEM, OBIA, Predictive Archaeology,

\section{INTRODUCTION}

Spatial modeling of GIS (Geography Information System) and remote sensing data development can be used in archaeological research, especially archaeological landscape approach. The archaeology landscape approach refers to the geographical landscape, also consider aspects of existing archaeological data. In this study, a spatial approach is used as a framework building of a model to describe issues related to archaeological data. The research area is on the karst region of Gunung Sewu in Gunung Kidul Regency, Yogyakarta. The Gunung Sewu karst covers 1,265 km² of total area and stretches across three provinces, including the Special Region of Yogyakarta (Gunung Kidul and Bantul Regencies), Central Java Province (Wonogiri Regency), and East Java Province (Pacitan Regency). Gunung Sewu divided into three blocks: the West, Central, and East Blocks which intersect with two depressions. The Central and Western Blocks are separated by the Baron-Ngringrong depression. It forms narrowing south of Ledok Wonosari; while the Middle and East Blocs were separated by the ancient Bengawan Solo valley [10].

MaxEnt model used to calculate the correlation between the dependent variable and the environment variable, then determine the subsequent presence in other areas. Using this method, we could obtain environmental variables that most influence the probability of a prehistoric site. Environmental variables were extracted from the Alos Palsar DEM image and multispectral Sentinel-2A images using GEOBIA segmentation and GIS data. Using this method in archeology research was expected to increase understanding of the existence of new sites extracted from the model.

Prehistoric human settlement sites had not all been identified and documented, due to extensive coverage of the Gunung Sewu karst area. The discovery of the archaeological site will greatly assist the process of determining as cultural resources so that preservation of the site can be done. Discovering new sites in the Gunung Sewu karst region be carried 
out both by government agencies and archaeological researchers continuously. The Gunung Sewu karst area had a wide area coverage, this encourages the need for macro-scale analysis of the landscape. Sentinel-2A images (resolution $10 \mathrm{~m}$ ) and Alos Palsar DEM (resolution $12.5 \mathrm{~m}$ ) which have a medium resolution have not been widely used to extract environmental variables as input for spatial modeling.

The maximum entropy method for modeling species distribution involves using a collection of known species localities as sample data along with relevant environmental factors to model the distribution of that species within a known geographical extent [15]. The Maxent program uses maximum entropy theory to create a probability distribution of a given species related to a series of environmental variables [9]. There are a number of theoretical and empirical similarities between biological species and archaeological sites. Humans, like animals and plants, preferentially target favourable locations for their activities, which in the case of humans includes economic, social and ritual activities. Other factors conditioning the successful emplacement of human investments in the landscape include elevation, topography, climate and the geologic substrate [16]. The location of prehistoric sites was very dependent on the condition of the surrounding resources as a subsistence of the prehistoric human community. Spatial modeling was carried out to understand the behavior of the pattern of prehistoric settelement cave selection so that it can be used to estimate the next archeological site. Model MaxEnt is used to obtain the probability distribution of sites in the research area using existing presence-only data and correlation with environmental variables.

\section{DATA AND METHODS}

\subsection{Pre-Processing Data}

The process of data analysis includes data collection, implementation of analysis (data processing and analysis), and evaluation of the results of data analysis [5]. Data processing and data analysis is the next stage after data collection. Preprocessing data is needed before the data analysis and processing stage. Preprocessing data in this study are: (1) Image Radiometric Correction to improve the quality of remote sensing image data. The image data used in this study is 1-level sentinel-2A imagery orthorectified with ToA (Top of Atmospheric) corrected. Image data is then reprocessed becomes level-2A to produce image data that has been corrected into BoA (Bottom of Atmospheric) or surface Reflectance, so it can be used in the analysis of the vegetation index. The reflectance correction results then converted to surface reflectance values using the dark object subtraction (DOS) method. (2) Geometric Correction in this study used Sentinel2A Multispectral level-1C image data. 1C-level image products have radiometric and geometric corrected including ortho-rectification and spatial registration correction in global reference systems with sub-pixel accuracy. Geometric corrections including ortho-rectification use UTM / WGS84 projections reference [14]. (3) The image masking process is done using ENVI 5.3 software with a research area located in Gunung Kidul district, Yogyakarta. The image masking process uses a boundary research vector data that is manually made following the boundary of the Sewu Mountain karst region in Gunung Kidul Regency, Yogyakarta. The result is the image area used in this study.

\subsection{Processing Data}

There are two variables inputs in model MaxEnt, the dependent variable, and the independent variable. The dependent variable is obtained from the archeological research reports which are then presented in a table form including spatial attributes and information. The independent variable in this study consisted of environmental variables (consisting of water sources, valleys, faults, slopes, heights, slope directions) extracted using remote sensing data. The dependent variable in this study is the archeological cave site in the Gunung Sewu karst area. This study used 68 cave points of prehistoric sites obtain from Thesis report by Jarwo Susetyo Edy Yuwono (Lecturer in the Department of Archeology, UGM), Rakhmi (2016), Kuswanto (2016) and spatial data from Archaeological Research Center of D.I. Yogyakarta, Yogyakarta. Archaeological cave sites are used as presence data for input of the model MaxEnt. MaxEnt model uses input dependent variables using the CVS format.

\subsection{MaxEnt model}

MaxEnt model used MaxEnt 3.4.1 software by entering the location data input for prehistoric settlement sites and independent variables as predictive variables. The MaxEnt software in this study uses the default settings to run the model iterations. MaxEnt model produces data: Prediction Maps (Prediction Maps); response curve (Response Curves) with an AUC (Area Under Curve); and Jackknife's results of analysis help researchers to interpret and understand the outcomes of MaxEnt model. Jackknife's results (the Jackknife results) are displayed in a bar chart to illustrate how the 
model is run using all input variables, as well as using all inputs but one variable and using only one variable [11]. These results are used to determine which variables have the greatest influence on probability on the MaxEnt model.

\subsection{Accuracy Test}

There are two statistical accuracy-test methods, first relying on sample data that has been taken as a reference source for accuracy assessment and the second method relies on independent data sources that are not used in sampling [12]. The model accuracy-test conducted by overlapping the results of the field survey and the archeological research report location data that had been done in the area with the results of the MaxEnt model probability map. then, high probability values tested for accuracy based on archaeological field survey in order to find archaeological remains indicating prehistoric settlement sites.

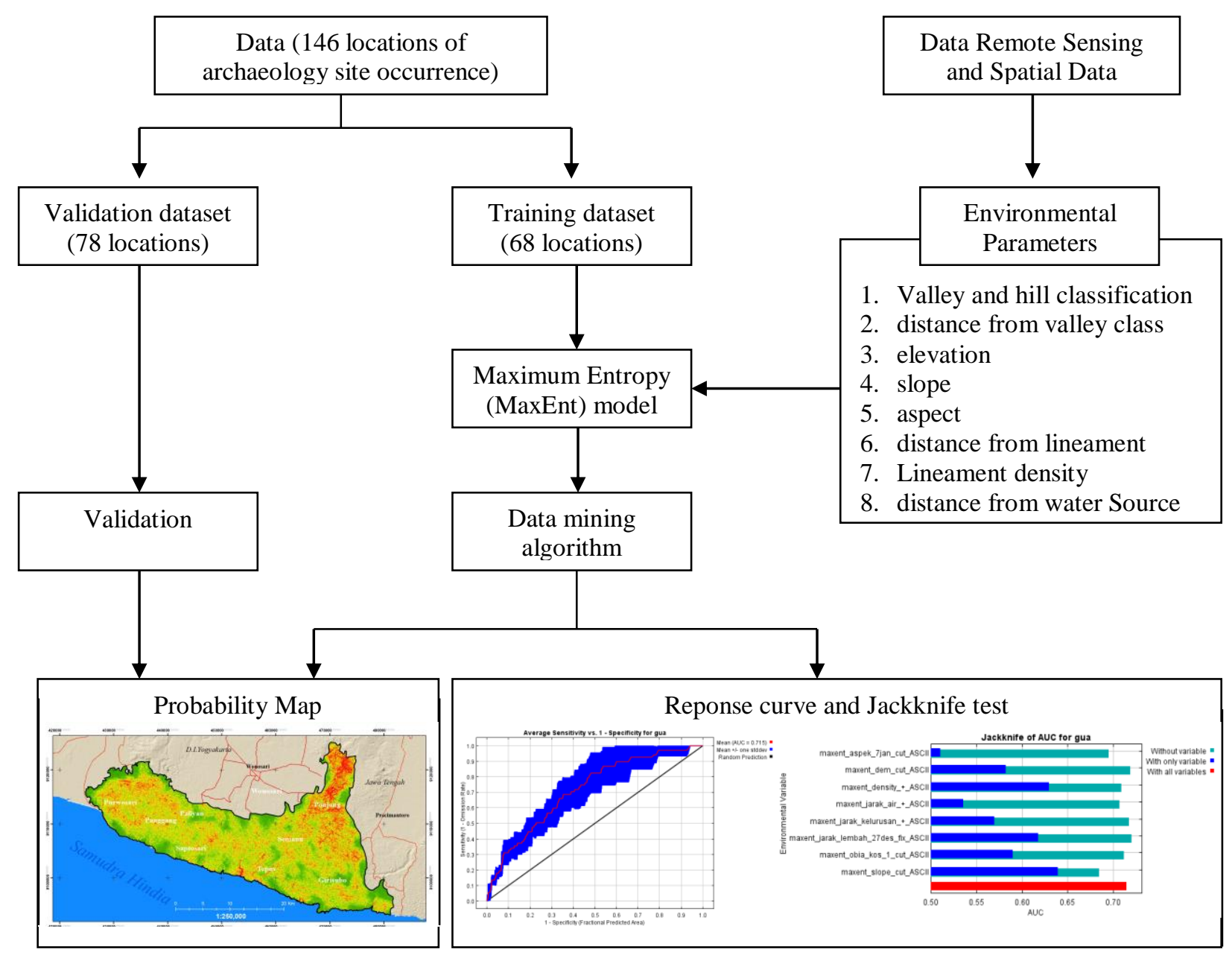

Figure. 1. The flowchart of method

\section{RESULT AND DISCUSSION}

\subsection{Environment Parameters of Prehistoric Cave Sites Extraction Results from DEM Alos Palsar and Sentinel- 2A Imagery}

The independent variable uses environmental variables extracted using the Alos Palsar DEM image, Sentinel-2A imagery and using GIS data, including: Valley and hill landforms extracted from DEM Alos Palsar images using OBIAbased automatic classification; extracted topographic form of Gunung Sewu region using Alos Palsar DEM data to produce Elevation maps, Slope Maps, Slope Facing Maps (Aspect); geology lineament maps extracted from visual 
interpretations of lineament from Sentinel-2A imagery; lineament density maps obtained from the results of visual interpretation of lineament were then analyzed using line density in ArcGIS software; and water resource variables obtained from SIG RBI data.

Dependent variables are a Presence data location of prehistoric settlement cave (or occupation) sites. It consists of 68 sites which have been recorded from 1997 until 2016. The presence data of these cave locations are displayed in CSV (comma delimited value) format. Cave sites that have potential as settlement caves are obtained from secondary sources, from the Excavation Research Center Arkenas (1997-2000), PTKA UGM (1998-2002), Yuwono (2013), Kuswanto (2016), and Rakhmi (2016).

The preparation of the independent variable data consists of several environmental variables, i.e.: biophysical components of water sources, geomorphology, and landforms. Landform can be represented in the elevation model or DEM which is then extracted into derivatives, i.e.: Slope, Aspect, Elevation. Independent variable using ASCII format raster with the same resolution that is $12.5 \mathrm{~m}$. The first step of modeling is OBIA classification of Landform to divide valley and hill, mapping several parameters (distance from valley class, elevation, slope, aspect, distance from lineament, Lineament, density, and distance from water Source).

\subsection{MaxEnt model}

MaxEnt model for predicting the presence of prehistoric settlement caves uses data from 68 prehistoric cave sites as presence data and eight environmental variables. MaxEnt model used Presence-only without Absence. Using the MaxEnt model with standard parameter settings will produce a model that is almost equivalent to a model that used absence data [3]. MaxEnt model output is in the form of a spatial prediction model for attendance, AUC (Area Under Curve), response curve, percentage contribution for each environmental variable, and Jackknife test. ROC method was built by selecting several data to be sampled [4]. A good model can be defined by a curve that maximizes sensitivity with a positive fraction value. This can be measured by calculating the Under Curve Area (AUC) [13]. MaxEnt model's performance in this study has a value of AUC 0.715 .

\section{Response Curve}

MaxEnt model produces a response curve of the relationship between the probability of the presence of prehistoric settlement caves and environmental variables which are input parameters. This curve (Figure 2) shows each variable influences the prediction of the presence of a prehistoric settlement cave location. There are two types of results shown from this model, the first in the form of curves for variables with continuous data types (continuous) and bar charts for variables with categorical (Categorical) data types.
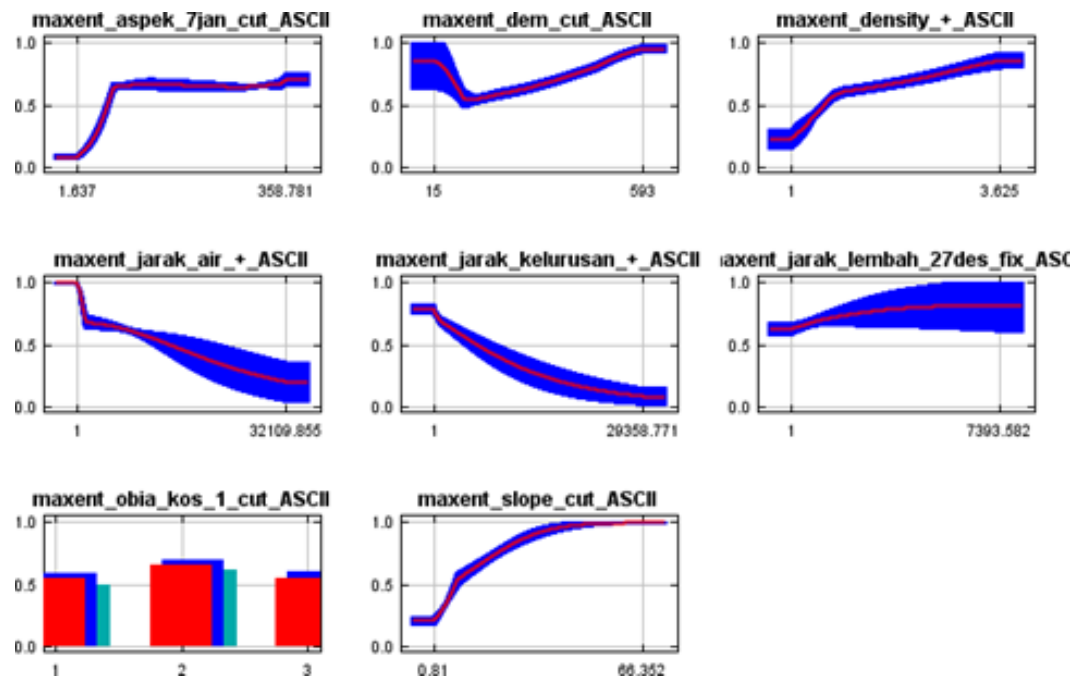

Figure. 2. The response curve for 8 environmental variables 
Caves with good condition for habitation and with resources available in their environs formed the main target of habitation. Life in temporary camps which had previously tended to be nomadic changed to more settled life in caves [7]. Caves can be divided into three group, first, cave ideal for habitation with characterized by proximity to a source of water, easy accessibility, good air circulation, and direct sunlight. Second, cave chareacterized by indirect lighting, sufficient air circulation, rather difficult to reach. And third, cave with bad air circulation, distant from the source of water, or far, and difficult to reach. Each cave will have a different combination of attributes, one cannot consider them in isolation from one to another. One cave may be near water, but have poor air circulation; another may be far from water but have good air circulation [7]. Such conditions can be determined by modeling to answer previous research questions, what characteristics are the most factors in determining the prehistoric caves for human occupation.

Analysis of the contribution of environmental variables is an analysis to determine the variables that have the greatest influence on the location of prehistoric occupational caves. This analysis contains the percent level of contribution of environmental variables and the level of the sequence of environmental variables on the location of prehistoric occupational caves. The MaxEnt program also produces an analysis table output of contributions based on percent and ranking levels of environmental variables (in percent) on the location of prehistoric settlement caves. The table of contribution of environmental variables analysis shown in Table 3. The environmental variables that have the greatest contribution are indicated by the lineament Density variable with a value of $28.5 \%$, Slope Variable has a value of $19.7 \%$, Aspect Variable has a value of $13.1 \%$, Distance variable from Water Source has a value of $11.7 \%$, the OBIA Classification of the Hill-Valley class has a value of $9.4 \%$, the Distance from Valley variable has a value of $7.5 \%$, the elevation variable has a value of $7 \%$, and the variable that has the lowest contribution value is Distance from lineament with a value of $3 \%$. The higher correlation between environmental variables and the location of prehistoric settlement caves influencing the contribution value (in percent).

MaxEnt model also has Permutation Importance (important constituent) output (see table 1) with the value of each environmental variable is Lineament Density has a value of $18.4 \%$, Slope has a value of $19.9 \%$, Aspect $20.4 \%$, Distance from Water Source has a value of $15.5 \%$, The OBIA Classification of valley-hill class has a value of 5.3\%, Distance from Valley has a value of $1 \%$, Elevation has a value of $5.5 \%$ and Distance from lineage has a value of $14 \%$. This table of important constituents means that information derived from each variable. If the analysis is done without these variables, then there is a decrease in AUC. The decrease (in a percentage) when the variable not included in the modeling input is shown in the permutation table. Slope direction variables have the highest value of $20.4 \%$, which means that if the direction toward the slope variable is not included in the modeling input then, there is a decrease in the AUC value of $20.4 \%$. While the lowest value is variable the distance from the valley with a value of $1 \%$ which means that the value only decreases the AUC value by $1 \%$ if it is not included in the modeling input.

Table 1. Environmental variables probability

\begin{tabular}{|c|c|c|c|c|c|}
\hline No & $\begin{array}{l}\text { Environmental } \\
\text { Variables }\end{array}$ & Contribution (\%) & $\begin{array}{c}\text { Permutation } \\
\text { importance }(\%)\end{array}$ & Value & Probability \\
\hline 1 & Lineament Density & 28.5 & 18.4 & $3.0-3.6$ & $0.75-0.85$ \\
\hline 2 & Slope & 19.7 & 19.9 & $30-70$ (degre) & $0.9-1$ \\
\hline 3 & Aspect & 13.1 & 20.4 & $\begin{array}{c}100-\begin{array}{c}150 ; 350-360 \\
\text { (degree) }\end{array} \\
\end{array}$ & $0.65-0.7$ \\
\hline 4 & $\begin{array}{l}\text { Distance from } \\
\text { Water Source }\end{array}$ & 11.7 & 15.5 & 0 - 1000 (meter) & $0.7-1$ \\
\hline 5 & $\begin{array}{c}\text { OBIA } \\
\text { classifications }\end{array}$ & 9.4 & 5.3 & Hill (Class) & 0.7 \\
\hline 6 & $\begin{array}{l}\text { Distance from the } \\
\text { valley }\end{array}$ & 7.5 & 1 & $\begin{array}{c}0-500 ; 3000-4000 \\
\text { (meter) }\end{array}$ & 0.85 \\
\hline 7 & Elevation & 7 & 5.5 & $\begin{array}{l}0-50 \text { (mdpl); } 500- \\
600 \text { (mdpl) }\end{array}$ & $0.85-0.95$ \\
\hline \multirow[t]{2}{*}{8} & $\begin{array}{l}\text { Distance from } \\
\text { Lineament }\end{array}$ & 3 & 14 & 0 - 5000 (meter) & $0.5-0.8$ \\
\hline & Total & $\begin{array}{l}99.9 \\
\end{array}$ & 100 & & \\
\hline
\end{tabular}


Table 1. shows that each environmental variable indicates the location of prehistoric settlement caves. In the table, the sequence of variable numbers is adjusted by the contribution value which has the greatest influence on the probability of the location of the prehistoric settlement cave. Number one (1) in the table (Lineament Density variable) has the most influence on the probability of the location of a settlement cave. The number eight (Distance variable from Lineament) has the smallest degree of influence in the probability of settlement cave locations. The sequence is suited with Jackkife's test result, numbers $1-5$ is a variable that has good information because if the variable eliminated, it will decrease the AUC value. While variables with numbers $6-8$ are variables that lack information because if the variable is omitted, the AUC value actually increases. The lineament density variable and the slope variable have a high probability value when modeling uses only this variable, thus showing that this variable has the best information of all environmental variables. The lineament density variable which has a high correlation with the location of prehistoric cave dwellings has a value of 3.0 - 3.6. Judging from the process of cave formation that occurs due to geological processes in lineament with the higher level of density lineament, the more possibilities to find prehistoric cave. Slope variable that has a cave location is in the range of 30-70 degrees. So that indicates that prehistoric cave dwellings generally occur on steep slopes. Aspect variable has values 100 - 150, 350 - 360 in the east to southeast direction, then in the direction towards the north slope. This variable indicates that there is a link between the direction towards the slope and the location of the cave dwelling. With the direction facing the slope is on the east to southeast is the direction where sunlight can enter through the mouth of the dwelling cave. It indicatating that the condition of the cave has a good angle of sun exposure as part of the comfort used for settlement. This indicates that the cave with a good radiation angle is a determining factor with a good level of air circulation as well. Whether or not the air circulation in the cave is much influenced by the extent or number of cave mouth, the direction of the cave mouth, the shape of the cave chamber, cave motphology, etc. [17]. Distance variable from a water source has a value of 0-1000 meters, the pattern of subsistence in prehistoric communities always requires water resources as its basic needs. So that the distance of the center of activity with water resources is one of the predictions where there are cave dwellings. Simanjuntak [17] provides a variable class of distance from water sources between $<2000$ meters as a class of "close" distance to water sources. In this research the curve results show that the distance of 0-1000 meters from the water source is the best distance from the discovery of the location of the prehistoric cave.

\section{Prehistoric Cave Sites Occurance Prediction}

MaxEnt model produces a probability map of prehistoric settlement cave places that have a range of values 0.000201672 - 1 as in Figure 3. This value indicates the most suitable environment for prehistoric settlement caves. The value close to 1 means that it has environmental suitability as a place of settlement for prehistoric humans. The value closer to 0 indicates that the environment is not suitable for prehistoric human occupation. This study aims to provide an overview of a suitable environment that has a high probability of being a settlement cave location. The output of the MaxEnt model is a probability map that can be used as a reference in the discovery of the existence of prehistoric settlement caves. 78 location validating dataset (from archaeological research) was used to accuracy assesment. The resulting MaxEnt model (probability map) were used overlay with the location validating dataset (fig. 3). In this case, the accuracy assessment resulted in $41 \%$ prehistoric sites that have high probability value (1-0.7), 28\% prehistoric sites have medium value (0.7-0.5) and $31 \%$ prehistoric sites have low value (0.5-0). This indicates that the probability map can determine the probability level of prehistoric sites. So that the decision to do archaeological excavation can refer to the probability value (the sites that have high probability value). Because not all the cave location has excavated by archaeologist.
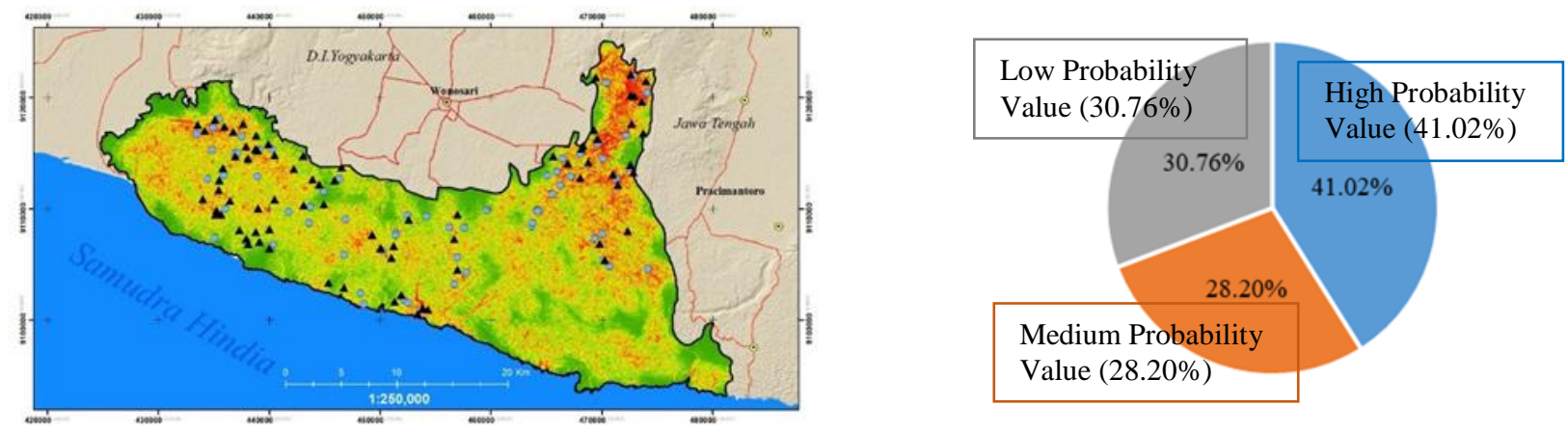

Figure 3. Probability Map and level probability value in archaeological sites 
Species distribution models provide at least two novel ways to systematically search for archaeological sites within a landscape or region. First, using species distribution models over the landscape, one can systematically check areas based on those with the highest probability. Second, one can visually interpret each location to identify potential locations in the field. As computer scientists have noted, humans often are more effective than computer algorithms in searching for patterns and anomalies in imagery or visual landscapes. Humans also are able to more easily include weighted relevance beyond simple presence-absence determinations [16].

One of the objectives of this study was to find the existence of a new prehistoric cave site. The maps show a high probability location (red color in fig.4) in areas that have never been discovered by an archaeological survey. The result can be used as a reference for the next archaeological survey. The archeological survey based on the MaxEnt model map (fig. 4) discovered six (6) new archeological cave locations. This survey is conducted by visiting a location where the area has a high probability of a probability map resulting from MaxEnt model. Areas that have a high probability, obtaining 4 cave point locations are Song Kere (fig. 5), Gua Dilem, Gua Senen, and Cave of Plelean. Whereas the two locations of the cave were found on the roadside to the area that had a high probability, the cave was: Song Kere 2 (naming the cave based on information from the local residents, while giving the name number 2 as a differentiator from other caves), and Cave in Purwodadi village.

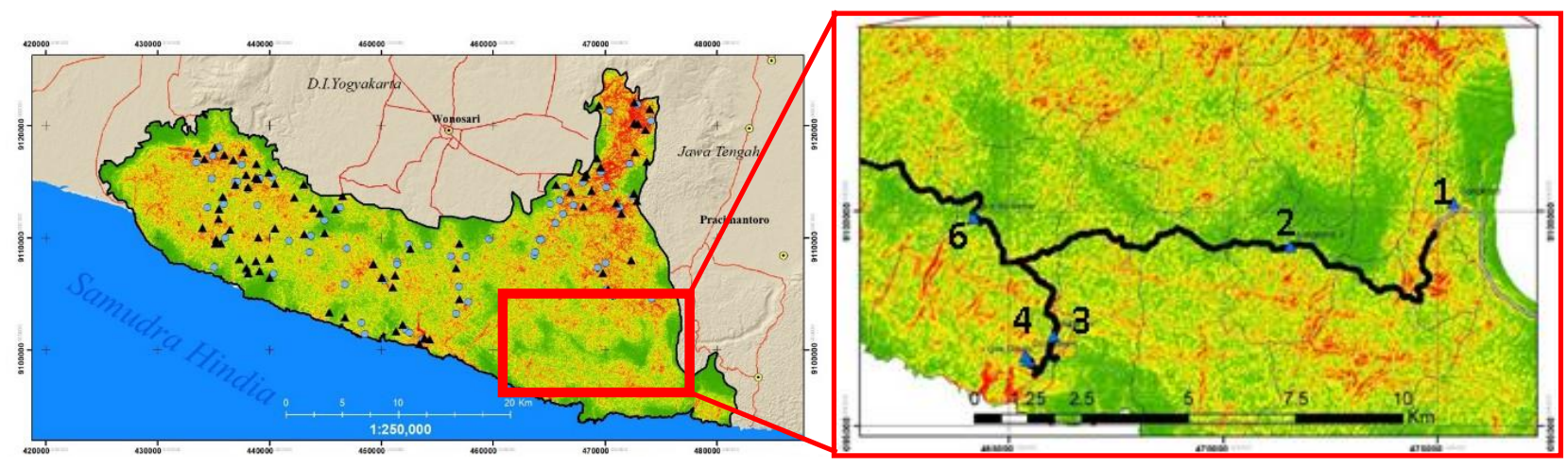

Figure 4. Probability Map of Prehistoric Settlement Cave Locations and Archeological Cave

The six locations of the cave have their respective probability values:

Table 2. Discovered in Archaeological survey 2018

\begin{tabular}{|l|l|l|c|c|}
\hline No. & \multicolumn{1}{|c|}{ Name of Cave / Song } & X & Y & Probability Value \\
\hline 1. & Song Kere & 475345 & 9100151 & 0.843063 \\
\hline 2. & Song Kere 2 & 471560 & 9099165 & 0.241951 \\
\hline 3. & Gua Dilem & 465491 & 9096497 & 0.741473 \\
\hline 4. & Gua Senen & 465414 & 9096620 & 0.737465 \\
\hline 5. & Gua Plelean & 466118 & 9096582 & 0.594479 \\
\hline 6. & Gua di desa Purwodadi & 464168 & 9099826 & 0.142339 \\
\hline
\end{tabular}

The use of a predictive GIS model serves a practical and cost-effective function by identifying areas where targeted surveys are most likely to reveal the presence of previously unknown sites at a time when there is increased pressure on landscapes for development [16]. The purpose of this study is to provide new archeological data that have never been done before. The use of MaxEnt model as a prediction of prehistoric cave sites can generate new data from archeology. Archaeological data commonly obtained from archaeological survey and archaeological excavation results. Using spatial modeling, determining archaeological excavation can be done efficiently. This research was used spatial modeling method from extracting remote sensing data and GIS data to obtain information on archaeological sites. So, this study can be used as a reference for the next related research. The location of prehistoric sites has several environmental parameters suitable for human occupation. Based on the probability value, it can be used to find new archeological sites and can determine the level of contribution of each variable in determining the suitable location for human occupation. 


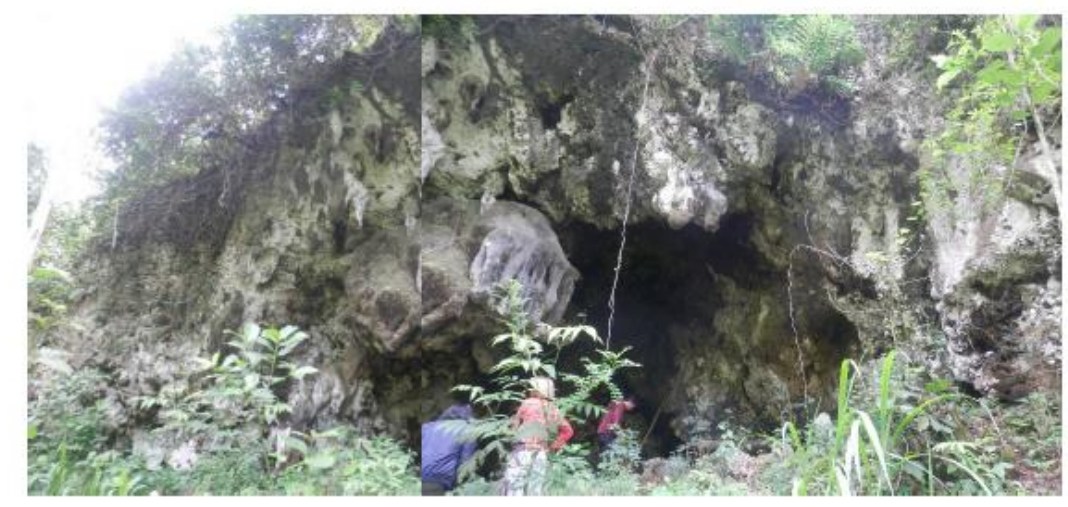

Figure 5. Archeological Cave

\section{CONCLUSION AND RECOMMENDATION}

MaxEnt model for prediction of prehistoric settlement cave sites uses ASCII raster format as an input of environment variables and CSV format as dependent variable inputs. Alos Palsar DEM image and Sentinel-2A imagery can be used for the extraction of environmental parameter information. Parameter extraction using the OBIA method (ruleset-based) to classify valley and hill landforms with good accuracy $(70.28 \%-81.13 \%)$. The data input were used 68 prehistoric settlement caves location and 8 environmental variables resulted in modeling performance with an AUC value of 0.715. In this study, the model shows good performance results indicated by the AUC value of 0.715. MaxEnt model also produces output in the form of tables of variables that most contribute of probability value. The table can be used to find out which variables most influence the suitability of the location prehistoric sites. Determination of the most influential variables can reference from the results of the Jackknife analysis test or the value of the contribution of each variable.

This study uses MaxEnt model to assist in solving archeological problems to determine which cave has high suitable for prehistoric human occupation cave. The result of assessment accuracy is 78 points divided into three classes, high probability classifications $(41 \%)$, medium (28\%), and low (31\%). High probability classes (32 cave locations), medium probability classes (22 cave locations), and low probability classes (24 cave locations). This indicates that probability modeling in this study can determine the probability level of prehistoric cave occupancy in the identified caves. So that the decision to make an archaeological excavation can refer to the probability value. The output model is a probability map with spatial information that is very helpful in determining the most potential areas. The probability map in this study is used as a reference in conducting searches to get the location of the new cave. The results of this study confirm that a predictive model can be used to find new archeological sites. Using new methods as a predicitive model in archaeological research hopefully increase better chance to answers archaeological questions. Reserach based on predictive model not only provide new method methods of interpreting data but also provide new insights into the past.

\section{REFERENCES}

[1] Steven J. Phillips, "A Brief Tutorial on Maxent," Available from URL: http://biodiversityinformatics.amnh.org/open_source/maxent/. Accessed on XXXX-XX-XX, 2017.

[2] Muhammad Kamal; Kasper Johansen, "Explicit Area-Based Accuracy Assessment for Mangrove Tree Crown Delineation using Geographic Object-Based Image Analysis (GEOBIA)," Earth Resources and Environmental Remote Sensing/GIS Applications VIII, pp. Proc. of SPIE Vol. 10428 104280I-1, 2017.

[3] Steven J. Phillips \& Miroslav Dudik, "Modeling of species distributions with Maxent: new extensions and a comprehensive evaluation," Ecography, Vol. 31, pp. 161-175, 2008. 
[4] R. A. Baldwin, "Use of Maximum Entropy Modeling in Wildlife Research," Entropy, pp. 854866, 2009.

[5] Sutanto, Metode Penelitian Penginderaan Jauh, Yogyakarta: Penerbit Ombak, 2013.

[6] Z. Zylshal, P. Danoedoro and E. Haryono, "An Object Based Image Analysis Approach ToSemi-Automated Karst Morphology Extraction," in www.researchgate.net, 2013.

[7] Prasetyo, B., Simanjuntak, T., \& Intan, F. S. Cave Settlement in the Gunung Sewu Area. In T. Simanjuntak, Gunungsewu Prehistoric. Jakarta: IAAI (Ikatan Ahli Arkeologi Indonesia). pp. 92-97. 2004.

[8] S. J. Phillips, R. P. Anderson and R. E. Schapire, "Maximum Entropy Modeling of Species Geographic Distributions," Ecological Modelling 190, pp. 231-259, 2006.

[9] S. H. Kailihiwa, "Using Maxent to Model the Distribution of Prehistoric Agricultural Features in a Portion of the," Http://spatial.usc.edu/wpcontent/wpcontent/uploads/2014/03/KailihiwaSolomonThesis.pdf., Master of Science, University of Southern California, 2015.

[10] J. S. Yuwono, "Karakteristik Geoarkeologis dan Proses Budaya Prasejarah Zona Poros Ponjong-Rongkop di Block Tengah Gunungsewu," Universitas Gadjah Mada, Yogyakarta, 2013.

[11] A. Healy, "A Comparison of Presence Only Suitability Models to Accurately Identify Prehistoric Agricultural Fields in Western," http://digitalrepository.unm.edu/geog_etds/24, New Mexico, 2016.

[12] P. Danoedoro, Pengantar Penginderaan Jauh Digital, Yogyakarta: Penerbit ANDI, 2012.

[13] Fourcade Y, Engler JO, Ro“ dder D, Secondi J, Mapping Species Distributions with MAXENT Using a Geographically Biased Sample of Presence Data:A Performance Assessment of Methods for Correcting Sampling Bias. PLoS ONE 9(5): e97122. DOI:10.1371/journal.pone.0097122 (2014).

[14] SUHET, Sentinel -2 User Handbook, ESA Standard Document, 2015.

[15] Phillips, Steven J., Miroslav Dudík, and Robert E. Schapire. "A Maximum Entropy Approach to Species Distribution Modeling." Proceedings of the Twenty-First International Conference on Machine Learning: 655-662. 2004.

[16] Gillespie, Thomas W.; Monica L. Smith, Scott Barron, Kanika Kalra and Corey Rovza. "Predictive modelling for archaeological sites:Ashokan edicts from the Indian subcontinent". CURRENT SCIENCE, VOL. 110 NO. 1916 10, 2016.

[17] Simanjuntak, T. (2004). Kronologi Hunian Di Gunung Sewu. In T. Simanjuntak, Prasejarah Gunung Sewu (pp. 258-265). Jakarta: IAAI (Ikatan Ahli Arkeologi Indonesia). 